\title{
RELAYOUT GUDANG BARANG JADI UNTUK MEMAKSIMALKAN KAPASITAS PRODUK JADI DENGAN MENGGUNAKAN METODE ACTIVITY RELATION CHART DAN SHARED STORAGE
}

\author{
Moch. Syayidi Sofyan, Atikha Sidhi Cahyana \\ Program Studi Teknik Industri \\ Universitas Muhammadiyah Sidoarjo Jawa Timur 61271 \\ syayidis02@gmail.com
}

\begin{abstract}
PT. XYZ constitute a business that move in sector of food in particular of Dry Noodle and Instan Noodle in Jl.Raya Suko KM3 Sidoarjo. In a build C of production that have three line machine of production and have one location warehouse baggage so that eventually Output from the three line machine will be saving in one warehouse the name is Finished Product Warehouse. Placement of the finished product that not organized well, make a build of production become not efficient. Layout is a main base in a industrial world. Plant layout or facilities layout can be defined as ordinances pengauran a facilities of factory to support the fluency. The purpose from this research is to give an suggestion to repair of layout about location of the finished product in a build $C$ of production. In this research use ARC ( Activity Relation Chart) method. ARC is an method or a simple technical in a planning of layout facility or ministry be based on the degree of relationship activities with qualitative assessment and inclined be based on opinions which is subjective from each facilities or ministry and method ( Shared Storage ). Shared storage is an method of preparation of the storage area be based on warehouse floor area condotions. As for the expected results from this research is can give an suggestion to repair of layout placement of the finished product that less ordinances well. As the result fro this research is the layout suggestion have value greater storage capacity from the initial layout with a capacity of 61 area, meanwhile for the initia capacity have value smaller as many as 44 storage area. In shared storage method the total value mileage on products A,B,C with initial layout is $142.376 \mathrm{~m}$. meanwhile on suggestion of layout there are a total mileage is $94,952 \mathrm{~m}$ with a difference 47,424 $\mathrm{m}$ from distance of initial layout.
\end{abstract}

Keywords: Layout, Transit Warehouse, ARC, Shared Storage

\section{PENDAHULUAN}

PT.XYZ merupakan perusahaan yang bergerak dalam bidang makanan khususnya Mie kering dan Mie instan yang hasilnya di pasarkan ke seluruh wilayah Indonesia dan sebagian juga diexport.Salah satu masalah yang sering dijumpai adalah tata letak barang di guang barang jadi, yang mana gudang barang jadi merupakan suatu tempat penyimpanan barang, baik bahan baku yang nantinya akan diproses, dalam industri manufaktur sering terjadi permasalahan yang terletak pada pengaturan tata letak gudang barang jadi.

Penempatan produk jadi yang belum terorganisir dengan baik, membuat gudang barang jadi tidak efisien dan tidak teratur dalam menyusun atau menempatkan produk jadi, penempatan produk jadi tidak seragam, dan lokasi koding atau stempel plastik terdapat jarak yang jauh dari area packing sehingga dapat mengakibatkan Back Track pada saat pengambilan material ke area packing, adapun beberapa permasalahan yang sama terjadi pada saat penempatan peralatan peralatan yang sudah tidak dipergunakan lagi masih ada diarea gudang transit, untuk saat ini pengunaan volume gudang transit masih kurang optimal.

\section{LANDASAN TEORI}

Menurut Mulcahy (1994) dalam Ardiansyah (2012) dalam Kuswoyo (2015) Gudang adalah suatu fungsi penyimpanan macam jenis produk yang memiliki unit penyimpanan dalam jumlah besar maupun kecil dalam jangka waktu saat produk dihasilkan oleh pabrik dan saat produk dibutuhkan oleh pelanggan atau stasiun kerja dalam fasilitas produksi. Gudang sebagai tempat yang dibebani tugas untuk menyimpan barang yang akan digunakan dalam produksi, sampai barang tersebut diminta sesuai dengan jadwal produksi. Dalam sistem pergudangan yang baik adalah sistem yang ampu memanfaatkan ruang untuk 
penyimpanan secara efektif agar dapat meningkatkan ruang penyimpanan yang kurang efektif yang mengakibatkan banyaknya produk yang tidak tertampung dalam gudang.

Dalam suatu pabrik, macam gudang dapat dibedakan menurut karakteristik material yang akan disimpan yaitu : (1) Raw Material Storage, gudang ini akan menyimpan setiap material yang dibutuhkan/digunakan untuk proses produksi. Lokasi gudang ini umumnya berada di dalam bangunan pabrik (indoor). Untuk jenis bahan tertentu bisa juga dikatakan di luar bangunan (outdoor). Yang mana hal ini dapat menghemat biaya gudang karena tidak membutuhkan bangunan spesial untuk itu. Gudang ini kadang kadang disebut juga sebagai stock room Karena memang fungsinya sebagai penyimpan stock untuk kebutuhan tertentu. (2) Working Process Storage. Dalam industri manufaktur sering kita jumpai bahwa benda kerja harus melalui beberapa macam operasi dalam pengerjaannya. Prosedur ini sering pula harus berhenti karena dari satu operasi ke operasi berikutnya waktu pengerjaan tidaklah sama, sehingga material harus menunggu sampai sampai mesin atau operator berikutnya tersebut siap mengerjakan. (3) Finished Goods Product Storage, kadang kadang disebut juga dengan gudang yang fungsinya adalah menyimpan produk-produk yang telah selesai dikerjakan.

Menurut Apple (1990) dalam Kuswoyo (2015) gudang harus dirancang dengan memperhitungkan kecepatan gerak barang yang bergerak cepat lebih baik diletakkan dekat dengan tempat pengambilan barang, sehingga sehinga mengurangi seringnya gerakan bolakbalik. Dalam gudang penyimpanan, faktor yang berpengaruh sangat besar terhadap penanganan barang ialah tata letak dan desain gedung dimana barang itu disimpan.

Pada umumnya tata letak pabrik yang terencana dengan baik akan ikut menentukan efisiensi dan beberapa hal akan juga menjaga kelangsungan hidup ataupun keberhasilan kerja suatu industri. Peralatan dan suatu desain produk yang baus akan tidak ada artinya akibat perencanaan layout yang sembarangan karena aktivitas produksi suatu industri secara nrmalnya harus berlangsung lama dengan tata letak yang selslu tidak berubah-ubah, maka setiap kekeliruan yang dibuat didalam perencanaan tata letak ini akan menyebabkan kerugian-kerugian yang tidak kecil. (Wignjosoebroto, 2003).

Pada umumnya macam macam proses industri akan juga mempengaruhi aktivitas perencanaan suatu pabrik. Pada continuous procces industry suatu studi kelayakan harus dilakukan mendalam. Faktor teknis maupun ekonomis harus dipertimbankan sebaik baiknya didalam langkah-langkah pemilihan ataupun penentuan mesin dan fasilitas peralatan penunjang produksi lainnya. (Wignjosoebroto, 2003).

Metode Activity Relation chart (ARC) adalah metode aliran bahan yang bisa diukur secara kualitatif menggunakan tolok ukur derajat kedekatan hubungan antara satu fasilitas (departemen) dengan lainnya. Nilai-nilai yang menurunkan derajat hubungan dicatat sekaligus dengan alasan-alasan yang mendasarinya dalam sebuah peta hubungan aktivitas (Activity Relationship Chart). Adapun suatu peta hubungan aktivitas dapat dikonstruksikan dengan prosedur sebagai: (1) Identifikasi semua fasilitas kerja atau departemen-departemen yang akan diatur tata letaknya dan dituliskan daftar urutannya dalam peta. (2) Dilakukan survei terhadap karyawan atau wawancara dari setiap departemen yang tertera dalam peta dan juga dengan manajemen yang berwenang. (3) Didefinisikan kritera hubungan antar departemen yang akan diatur letaknya berdasarkan derajat kedekatan hubungan serta alasan masing-masing dalam peta, selanjutnya tetapkan nilai hubungan tersebut ntuk setiap hubungan aktivitas antar deparemen yang ada dalam peta. (4) Didiskusikan hasil penilaian hubungan aktivitas yang telah ditetapkan tersebut dengan kenyatan dasar manajemen. Secara bebas beri kesempatan untuk evaluasi atau perubahan yang lebih sesuai. Checking, rechecking dan tindakan koreksi perlu dilakukan agar ada konsistensi atau kesamaan presepsi dari beberapa yang terlibat dalam hubungan kerja.

Sedangkan Metode Shared Storage Menurut Francis (1992) dalam Indramawan (2015) dalam menentukan layout dengan menggunakan metode sharedstorage ada lima variable yang harus diketahui yaitu: (1) Lama Waktu work in process. (2) Waktu Pengiriman masingmasing material. (3) Jumlah material setiap pemesanan. (4) Frekuensi pemesanan pada tiap 
periode waktu. (5) Jarak pada tiap-tiap penyimpanan terhadap pintu keluar masuk. (6) Kebutuhan ruang atau space.

Dengan ini proses penyimpanan material berdasarkan metode shared storage harus diurutkan pada area yang paling dekat dan area terjauh pada proses pengiriman pintu keluar dan pintu masuk, maka penempatan material yang akan dikirim diletakan pada area terdekat dan slot-slot yang kosong dalam gudang transit.

\section{METODOLOGI PENELITIAN}

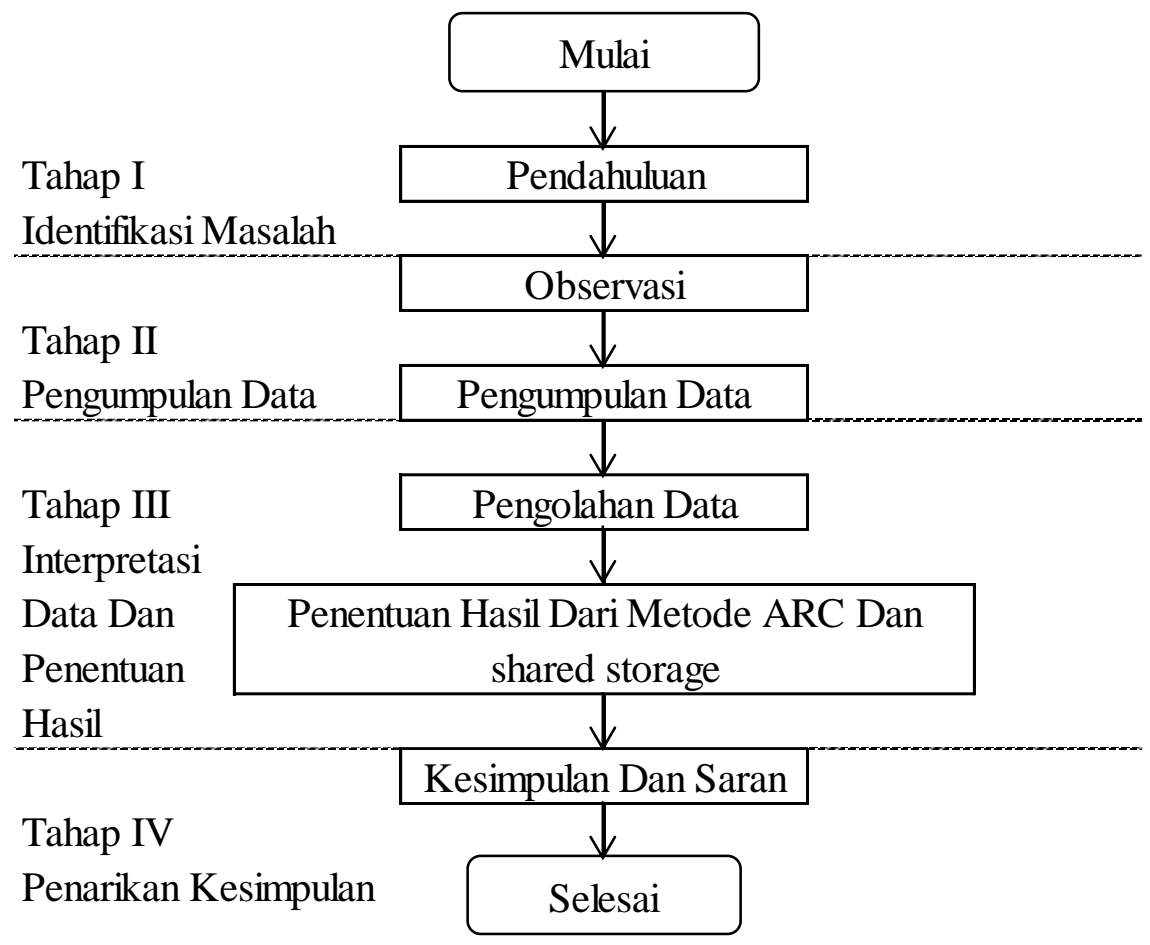

Gambar 1. Diagram Alir Penelitian

\section{a. Pendahuluan}

Studi pendahuluan ini dilaksanakan bertujuan untuk memperoleh masukan mengenai objek yang diteliti. Diharapkan dapat memperoleh informasi mengenai permasalahan yang diangkat dalam penelitian dan variabel-variabel yang terkait dalam masalah pada gudang transit di PT. XYZ. Studi pedahuluan dalam penelitian ini dilakukan dengan melakukan pengamatan, pengukuran, melihat data yang diperlukan, dan wawancara dengan pihak perusahaan.

\section{b. Observasi}

Metode observasi, yaitu metode pengumpulan data dengan cara pencatatan langsung di lapangan tentang kondisi aktual layout yang ada. Berdasarkan metode observasi ini, di harapkan mendapatkan data berupa: (a) Data primer, yaitu data yang diperoleh langsung dari lapangan terhadap obyek pengamatan, misalnya wawancara langsung dengan semua pihak yang terkait. (b) Data sekunder, yaitu data yang diperoleh dari pihak perusahaan, yang dapat berupa bukti-bukti dokumentasi (arsip, foto, dll), jurnal-jurnal, atau catatan di perusahan. (c) Melakukan studi pustaka dari berbagai literatur. 


\section{c. Studi Literatur}

Studi literatur ini dilaksanakan dengan melakukan studi pustaka melalui bukubuku referensi untuk mendapatkan data yang telah berhubungan dengan judul tugas akhir yang telah penulis angkat.

\section{d. Pengumpulan Data}

Sumber data primer dari penelitian ini akan diambil dari studi lapangan, wawancara dengan karyawan atau perusahaan. Sedangkan sumber data sekunder didapat dari beberapa sumber buku-buku dan jurnal.

\section{e. Pengolahan Data}

Data yang telah dikumpulkan, lalu diolah dengan metode yang digunakan adalah Activity Relationship Chart dan shared storage yang kemudian akan digunakan untuk menentukan pemecahan masalah yang terjadi pada gudang transit di PT.XYZ.

\section{f. Kesimpulan Dan Saran}

Kesimpulan dan Saran dilakukan setelah adanya hasil dari pengolahan data dan pemecahan masalah.

\section{HASIL DAN PEMBAHASAN}

Pengumpulan data dilakukan untuk menunjukkan bagaimana langkah-langkah yang diambil untuk mengumpulkan data yang akan digunakan untuk melakukan penelitian. (1) Teknik observasi dikaukan dengan mengadakan tanya jawab langsung dengan pihak perusahaan terutama pada karyawan langsung khususnya karyawan yang ada pada bagian produksi beserta staff terkait masalah pada penataan barang jadi. (2) Pengumpulan datadengan cara mengadakan pengamatan langsung ke lapangan dan melakukan studi pustaka terkait sumber-sumber yang nantinya akan diolah untuk menunjang penelitian baik data skunder maupun data primer.

Hasil pengumpulan data selanjutnya dilakukan dengan pengolahan data yaitu dengan menggunakan metode activity relation chart dimana metode ini adalah tahapan penentuan drajat hubungan antara fasilitas dengan fasilitas yang lain yang nantinya akan menghasilkan sebuah layout dan fasilitas mana yang perlu didekatkan dan mana yang tidak perlu didekatkan.

Adapun metode shared storage adalah metode yang digunakan untuk menentukan ruang atau slot-slot pada bagian gudang transit.

\section{a. Analisa Fasilitas}

Fasilitas-fasilitas yang ada pada PT.XYZ di gudang transit untuk diidentifikasi dengan bertujuan untuk mencari drajat kedekatan fasilitas-fasilitas yang nantinya akan didekatkan jarak antara fasilitas dengan fasilitas yang lain, fasilitas yang termasuk dalam fasilitas sementara adalah fasilitas yang memiliki hubungan secara langsung dengan aktifitas-aktifitas fisik proses penataan barang di area transit. Adapun list fasilitas sementara dapat terlihat pada tabel 1yaitu tabel list smentara.

Tabel1. List Sementara.

\begin{tabular}{|c|c|c|c|c|c|}
\hline No & Fasilitas & Keterangan & $\mathbf{p}$ & $\mathbf{L}$ & Luas $\left(\mathbf{m}_{2}\right)$ \\
\hline 1 & Area Stapel & Area untuk melakukan proses penataan mi & 8 & 6 & 48.0 \\
\hline 2 & $\begin{array}{l}\text { Ruang } \\
\text { Stempel }\end{array}$ & $\begin{array}{l}\text { Tempat melakukan proses pemberian kode } \\
\text { produksi yang nantinya untuk diambil dan } \\
\text { diberikan ada personel kemas }\end{array}$ & 2 & 1 & 2.0 \\
\hline 3 & $\begin{array}{l}\text { Meja } \\
\text { Kemas }\end{array}$ & $\begin{array}{l}\text { Tempat untuk menata mi sebelum diletakkan } \\
\text { diatas pallet }\end{array}$ & 1 & 1 & 1.0 \\
\hline
\end{tabular}




\begin{tabular}{|c|c|c|c|c|c|}
\hline No & Fasilitas & Keterangan & $\mathbf{p}$ & $\mathbf{L}$ & $\operatorname{Luas}\left(\mathbf{m}_{\mathbf{2}}\right)$ \\
\hline 4 & Pallet & $\begin{array}{l}\text { Wadah untuk penataan mi sebelum dilakukan } \\
\text { transfer ke area transit }\end{array}$ & 1.1 & 1.1 & 1.2 \\
\hline 5 & Layer Box & $\begin{array}{l}\text { wadah untuk kertas bekas yang nantinya } \\
\text { dipruntukan alas mi diatas palet }\end{array}$ & 3 & 2 & 6.0 \\
\hline 6 & $\begin{array}{l}\text { Penunjang } \\
\text { (Plastik) }\end{array}$ & $\begin{array}{l}\text { Digunakan untuk mengemas mi yang } \\
\text { menggunakan material plastik }\end{array}$ & 1.1 & 1.1 & 1.2 \\
\hline 7 & $\begin{array}{l}\text { Penunjang } \\
\text { (Roll) }\end{array}$ & $\begin{array}{l}\text { Digunakan untuk mengemas mi melalui } \\
\text { mesin packing }\end{array}$ & 1.1 & 1.1 & 1.2 \\
\hline 8 & $\begin{array}{l}\text { Penunjang } \\
\text { (Box } \\
\text { Karton) }\end{array}$ & $\begin{array}{l}\text { Digunakan untuk mengemas mi yang sudah } \\
\text { terbungkus secara individual pack }\end{array}$ & 1.2 & 1.2 & 1.4 \\
\hline \multicolumn{5}{|c|}{ Total } & 62.1 \\
\hline
\end{tabular}

Dari data list sementara dapat terlihat beberapa jarak antara fasilitas dengan failitas yang lain, setelah itu akan dilakukan pengukuran jarak tiap antar fasilitas. Jarak yang dapat diukur adalah jarak fasilitas-asilitas yang nantinya perlu didekatkan dengan lokasi pengemasan mi. sebelum melakukan pengukuran jarak antara fasilitas dapat diketahui terlebih dahulu aliran bahan pada saat produksi berlangsung.

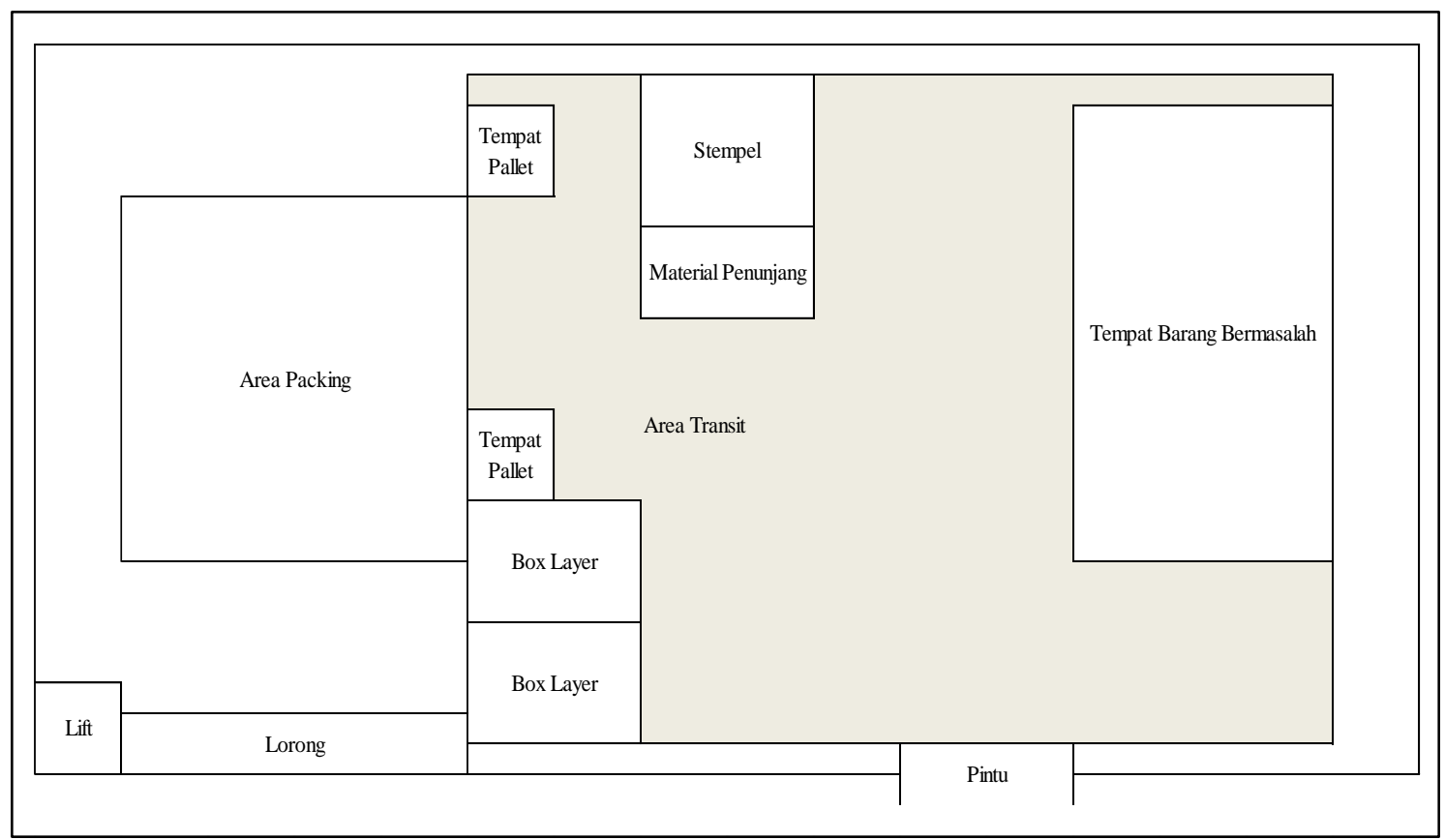

Gambar 2. Layout awal keseluruhan sebelum perbaikan

Gambar 2 adalah gambar sebelum dilakukan perbaikan dapat dilihat ada beberapa fasilitas yang perlu didekatkan dan ada beberapa fasilitas yang tidak dikehendaki untuk saling berdekatan degan area pengemasan seperti (1) Tempat Pallet (2) Box Layer (3) Materal Penunjang (4) Stempel.

Gambar 3 adalah standard penggambaran drajat aktivitas yang dilakukan pada PT.XYZ berdasarkan metode Activity Relation Chart. 


\begin{tabular}{|c|l|c|c|}
\hline $\begin{array}{c}\text { Derajat Nilai } \\
\text { Kedekatan }\end{array}$ & \multicolumn{1}{|c|}{ Deskripsi } & Kode Garis & Kode Warna \\
\hline A & Mutlak & $\overline{\overline{\overline{ }}}$ & Merah \\
\hline E & Sangat Penting & $\overline{\overline{ }}$ & Oranye \\
\hline I & Penting & $\overline{\text { Hijau }}$ \\
\hline O & Cukup/Biasa & & Biru \\
\hline U & Tidak Penting & Tidak Ada & Tidak Ada \\
\hline X & Tidak Dikehendaki & $/$ & Coklat \\
\hline
\end{tabular}

Gambar3. Standard Penggambaran Derajat Hubungan Aktivitas

\begin{tabular}{|c|l|}
\hline A & Mutlak perlu Didekatkan \\
E & Sangat penting Untuk Didekatkan \\
I & Penting Untuk Didekatkan \\
O & Cukup \\
U & Tidak Penting \\
X & Tidak Dikehendaki Untuk Berdekatan \\
\hline
\end{tabular}

Gambar 4. Derajat Hubungan

Pada saat proses pengepakan, area stempel dan area pengepakan yang memliki jarak yang mutlak harus didekatkan, dikarenakan selain menggunakan tenaga kerja manusia pemindahan atau pengambilan bahan penunjang plastik terdapat jarak yang cukup jauh yaitu sepanjang 45 meter yang sebaiknya harus saling berdekatan antara tempat stempel dan area pengemasan tersebut.

Pada saat proses produksi memang memiliki hirarki yang berurutan baik dari proses pengepakan dan proses pengambilan bahan penunjang terkait minimnya ruang tansit akibat adanya slot-slot ksong yang dipegunakan untuk tempat fasilitas bahan penunjang yang seharusnya area transit hanya ditempati produk jadi saja.

Pada stasiun kerja di area transit jika penempatan bahan penunjang dan area pengepakan saling berjauhan maka secara tidak langsung ruang transit semakin berkurang dan pada saat pengambilan material penunjang juga dapat memakan waktu yang cukup lama, adapun untuk menhindari jarak yang cukup jauh tersebut, area stempel dan area pengepakan sangatlah penting untuk saling berdekatan. Hubungan kedekatan fasilitas pada ARC merupkan seberapa jauh atau dekat sebuah fasilitas dengan fasilitas yang lain yang nantinya hubungan antara fasilitas ini akan digunakan sebagai pertimbangan pemindahan fasilitas.

Dari pengumpulan data dari tabel fasilitas sementara, maka peneliti dapat mengolah dengan metode Activity Relationship Chart ( ARC ). 


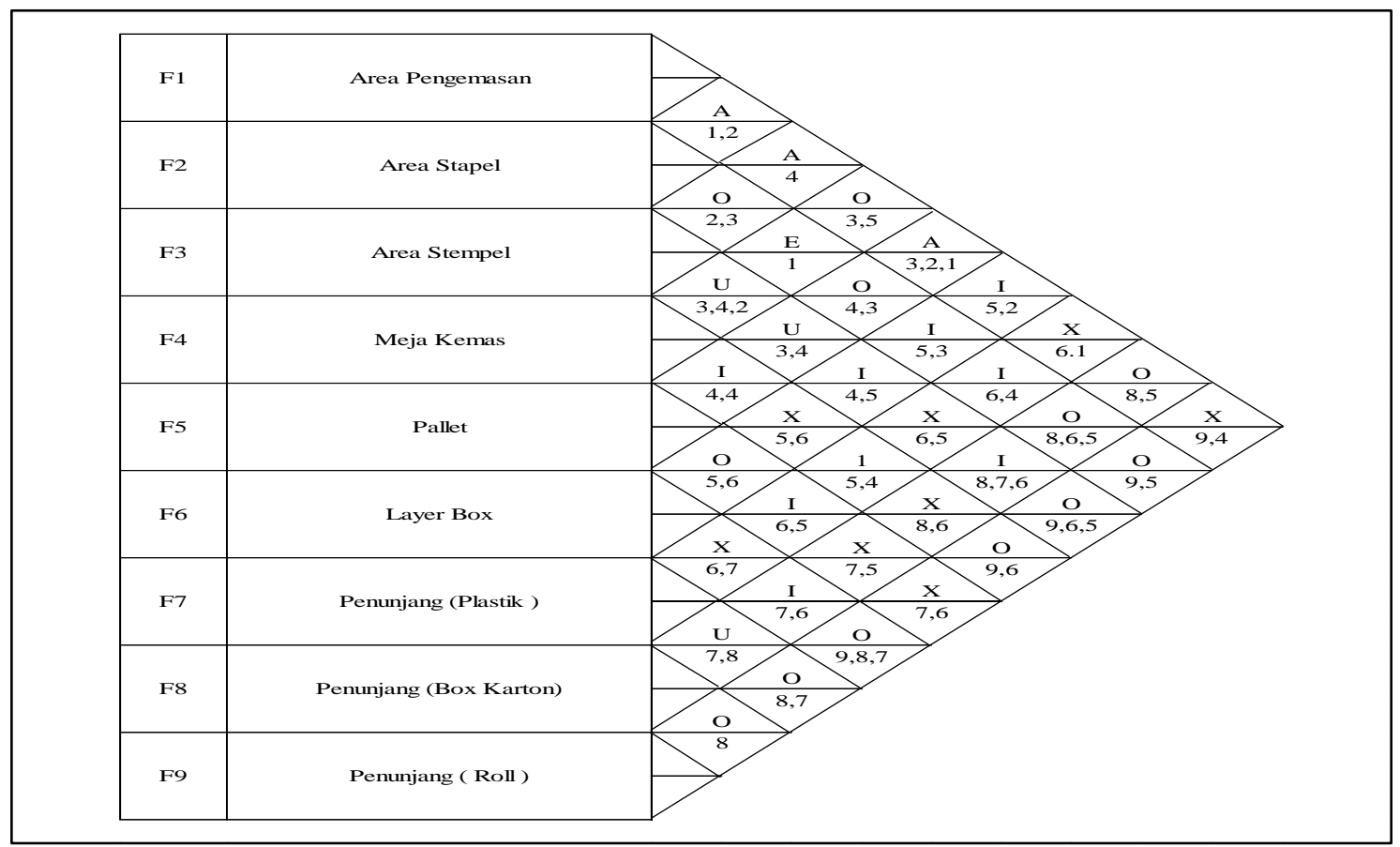

Gambar 5. Peta Hubungan Aktifitas di Bagian Area Pengemasan

Tabel 2. Derajat Kedekatan Antar Fasilitas

\begin{tabular}{|c|l|c|c|c|c|c|c|}
\hline \multirow{2}{*}{ Nomor Dan Bagian } & \multicolumn{7}{|c|}{ Derajat Kedekatan } \\
\cline { 2 - 8 } & A & E & I & O & U & X \\
\hline a & Area Pengemasan & $1,2,4,3$ & - & 5,2 & $3,8,5$ & - & $6,4,1,9$ \\
\hline b & Area Stapel & - & 1 & $5,3,4,6$ & $8,6,5,4,3,9$ & - & - \\
c & Area Stempel & - & $4,5,8,7,6$ & 4,5 & $9,6,5$ & $3,2,4$ & - \\
d & Meja Kemas & - & - & 4,5 & 9,6 & $5,6,8$ & - \\
e & Pallet & - & - & 6,5 & 5,6 & - & $7,6.6$ \\
f & Layer Box & - & - & 7,6 & $3,8,7$ & - & 6,7 \\
g & Penunjang Plastik & - & - & - & 8,7 & 7,8 & - \\
h & Penunjang Box Karton & - & - & - & 7 & - & - \\
i & Penunjang Roll & - & - & - & 8 & - & - \\
\hline
\end{tabular}

Selanjutnya dari lembar kerja pada proses pengepangan di gedung produksi $\mathrm{C}$ tersebut maka selanjtnya dapat menentukan letak masing masing bagian atau mesin sesuai dengan derajat keterdekatan dari masing-masing bagian atau mesin tersebut.

Berdasarkan hasil dari data analisa fasilitas dengan jarak perpindahan fasilitas maka penulis akan membuat travel chart berdasakan fasilitas untuk sementara adalah jumlah ukuran handlig volumenya sama.

Tabel 3. Analisa Moment Trial I

\begin{tabular}{|c|c|c|}
\hline \multicolumn{2}{|c|}{ Forward Distance Dari Jarak Diagonal } & $\begin{array}{c}\text { Backward Distance } \\
\text { Dari jarak Diagonal }\end{array}$ \\
\hline 1 & 85 & 85 \\
2 & 124 & 62 \\
3 & 57 & 19 \\
\hline
\end{tabular}




\begin{tabular}{|c|c|c|}
\hline \multicolumn{2}{|c|}{ Forward Distance Dari Jarak Diagonal } & $\begin{array}{c}\text { Backward Distance } \\
\text { Dari jarak Diagonal }\end{array}$ \\
\hline 4 & 52 & 13 \\
5 & 25 & 10 \\
6 & 0 & 0 \\
7 & 35 & 10 \\
8 & 0 & 0 \\
Total & $\mathbf{3 7 8}$ & $\mathbf{1 9 9}$ \\
\hline \multicolumn{2}{|c|}{ Total Forward + Backward } \\
\hline
\end{tabular}

Tabel 4. Analisa Moment Trial II

\begin{tabular}{|c|c|c|}
\hline \multicolumn{2}{|c|}{ Forward Distance Dari Jarak Diagonal } & $\begin{array}{c}\text { Backward Distance Dari } \\
\text { jarak Diagonal }\end{array}$ \\
\hline 1 & 56 & 56 \\
2 & 28 & 14 \\
3 & 0 & 0 \\
4 & 96 & 24 \\
5 & 15 & 3 \\
6 & 42 & 7 \\
7 & 105 & 15 \\
8 & 16 & 2 \\
Total & $\mathbf{3 5 8}$ & $\mathbf{1 2 1}$ \\
\hline Total Forward + Backward & $\mathbf{4 7 9}$ \\
\hline
\end{tabular}

Setelah dilakukan analisa data moment trial I dan II dapat diketahui perbedaan nilai antara moment I dan II yaitu total trial I terdapat nilai 338 sedangkan nilai trial II mempunyai nilai 479 yang berarrti nilai yang lebih kecil yang nantinya akan digunakan untuk alternatif usulan relayout gudang barang jadi.

Setelah diketahui perbedaan nilai kedunya selanjutnya dilakukan redesain ruangan secara manual dengan menggunakan acuan analisa activity relation chart dan analisa from to chart dan dicari total jarak material handlingnya yang berdasarkan pada analisa from to chart.

b. Analisa Penurunan Jarak Material Handling

Analisa ini digunakan untuk mengetahui besarnya total jarak material handling pada tata letak usulan. Untuk mengetahui penurunan total jarak, maka jarak total pada trial I dikurangi dengan total jarak trial II dan hasilnya sebagai berikut:

= Total Jarak Trial I - Total Jarak Trial II

$=577-479$

$=98$

Dihitung dalam presentase menjadi:

$=\frac{\text { Total Jarak Trial I }- \text { Total Jarak Trial II }}{\text { Total Jarak Trial II }} \times 100 \%$

$=\frac{577-479}{479} \times 100 \%$

$=20.4 \%$

Sumber : Nasution dkk (2015) 


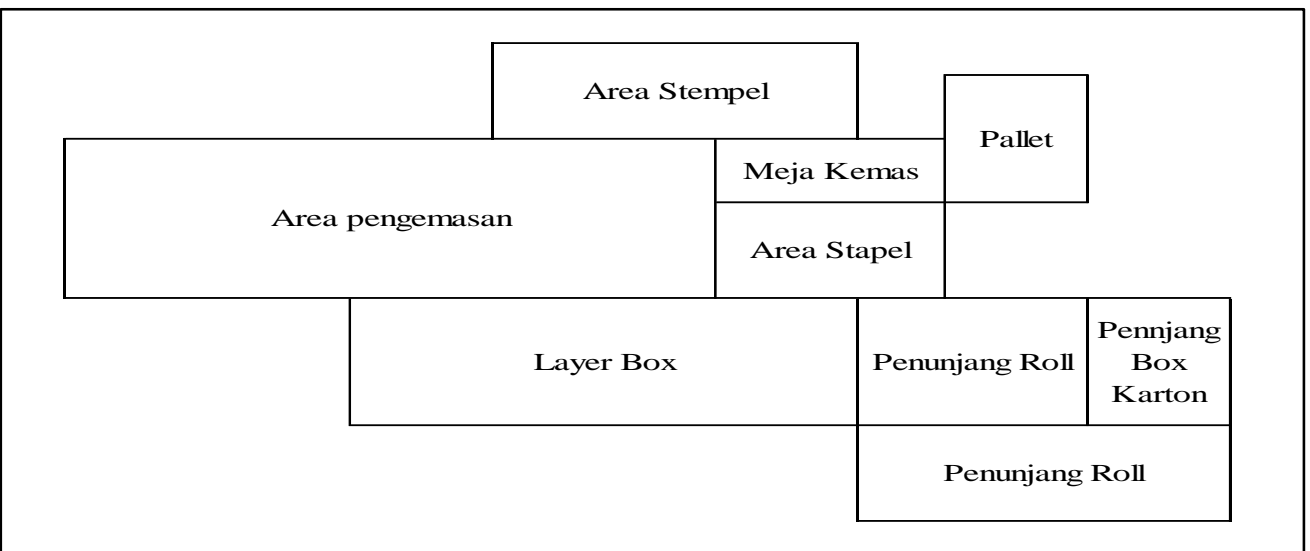

Gambar 6. Hasil Layout Dari Analisa Activity Relation Chart/

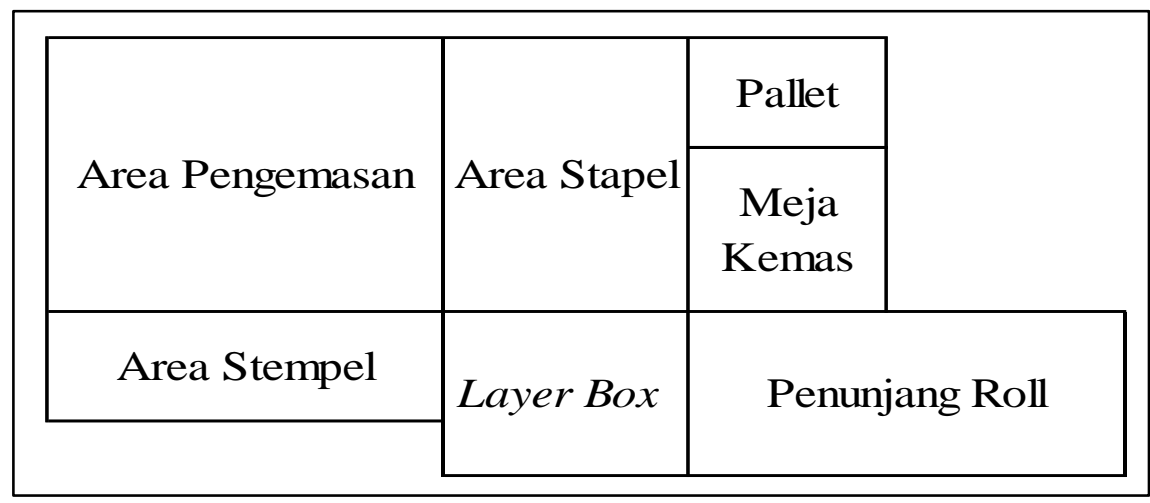

Gambar 7. Gambar usulan dari hasil analisa menggunakan Activity Relation Chart.

Untuk menghemat area penyimpanan dengan dilakukan 2 tingkat yang terdiri dari 72 Dos dalam 1 Pallet dengan dimensi per dos $\mathrm{P}=39 \mathrm{~cm} \mathrm{~L}=35 \mathrm{~cm} \mathrm{~T}=15.5 \mathrm{~cm}$.

Dimensi $=39 \times 35 \times 15.5 / 100=212 \mathrm{~cm}^{2}$

Panjang $=39 \mathrm{~cm}$

Lebar $=35 \mathrm{~cm}$

Tinggi $=15.5 \mathrm{~cm}$

dengan luas yang tersedia yaitu $251.7 \mathrm{~m}^{2}$. Dilakukan untuk mempermudah dalam penyusunan produk ke area penyimpanan juga untuk menghemat pemanfaatan ruang. Jadi luas 1 area penyimpanan yang dibutuhkan adalah:

Luas area penyimpanan $=$ Panjang Produk $x$ Lebar produk $/ 100=13.6 \mathrm{~cm}^{2}$

Luas area penyimpanan $=39 \times 35 / 100=13.6 \mathrm{~cm}^{2}$

Setelah diketahui beberapa data dimensi produk maka selanjutnya akan dicari banyaknya area penyimpnan yang dibutuhkan, untuk mencari banyaknya area yang dibutuhkan adalah :

Kebutuhan area penyimpanan $=\frac{\text { Total Jumlah Produk }}{\text { Banyaknya Produk Dalam 1Palet }}$

Kebutuhan area penyimpanan $=\frac{4394}{72}=61$ Area

Maka dari banyaknya produk 4394 per hari membutuhkan ruang penyimpanan untuk 61 area dengan kapasitas gudang transit yaitu $251.7 \mathrm{~m}^{2}$.

Pemanfaatan ruang gang atau allowance untuk menggerakkan material handling menggunakan handkliftsebagai alat angkut produknya.Jadi allowance yang dibutuhkan berdasarkan kebutuhan untuk jalur sesuai dengan ukuran dimensi handklift. Penentuan 
luas gang yang ada pada handklift saat membawa produkdengan Panjang 1,40 m, dan lebar $0,70 \mathrm{~m}$.

untuk mengatahui allowance yang diperlukan yaitu dengan menggunakan perhitungan sebagai berikut:

Diagonal $=\sqrt{\mathrm{p}^{2}+1^{2}}=\sqrt{1.40^{2}+0.70^{2}}=1.5 \mathrm{~m}$

Dengan mengetahui allowance yang diperlukan maka dapat ditentukan lebar gang seluas $1.5 \mathrm{~m}$.

Jarak tempuh antara material handling adalah mulai dari pintu (I/O) menuju ke area penyimpanan perhitungan jarak dilakukan dengan menggunakan metode Rectilinear Distance. Jarak diukur sepanjang lintasan dengan menggunakan garis tegak lurus (ortogonal) satu dengan yang lainya terhadap titik dari masing-masing area penyimpanan dengan cara :

Keterangan :

$$
d i j=|x-a|+|y-b|
$$

$d i j \quad=$ jarak slot $i j \mathrm{ke} \mathrm{titik} \mathrm{I} / \mathrm{O}$

$x \quad=$ Titik awal perhitungan $\mathrm{I} / \mathrm{O}$ pada sumbu $\quad x$ (horizontal)

$a \quad=$ Jarak titik tengah tujuan trhadap sumbu $\quad x$

$y \quad=$ Titik awal perhitungan $\mathrm{I} / \mathrm{O}$ pada sumbu $\quad y$ (vertical)

$b \quad=$ Jarak titik tengah tujuan terhadap sumbu $\quad y$

Contoh perhitungan:

$d 1.1=|x-a|+|y-b|=|0-8.25|+|0-5.50|=13.75 m$

$d 2.1=|x-a|+|y-b|=|0-4.20|+|0-3.70|=7.9 \mathrm{~m}$

c. Jarak Tempuh Mutasi Barang Jadi Dengan Tata Letak Awal

Berdasarkan data pada lampiran 4 yaitu jarak tempuh mutasi barang jadi per bulan yang menuju pintu keluar dengan masing-masing produk yaitu produk A yang mempunyai nilai $67600 \mathrm{~m} /$ Bulan, sedangkan untuk produk B mempunyai nilai 34112 $\mathrm{m} /$ Bulan, dan produk C mempunyai nilai $40664 \mathrm{~m} /$ Bulan.

\section{d. Jarak Tempuh Mutasi Barang Jadi Dengan Tata Letak Usulan}

Adapun jarak tempuh mutasi barang jadi per bulan yang menuju pintu keluar dengan masing-masing produk yaitu produk A yang mempunyai nilai $46592 \mathrm{~m} / \mathrm{Bulan}$, untuk produk B mempunyai nilai 27456 m/Bulan, dan produk C mempunyai nilai 20904 m/Bulan.

Maka dengan adanya data perbandingan jarak tempuh materialhandling yang berdasarkan pada lampiran 4 maka dapat diketahui tata letak jarak tempuh material handling usulanlebih kecil dari tata letak material handling awal.

\section{e. Peletakan Area Penyimpanan}

Setelah mengetahui kebutuhan ruangan maka dapat ditentukan jumlah area yang dapat diperoleh luas gudang adalah $17 \times 15-3.3=251.7 \mathrm{~m}^{2}$. Maka dapat diatur dengan sedemikian rupa susunan peletakan area penyimpanan pada gudang transit yang berdasarkan data kebutuhan ruang(lebar gudang transit dan luas area penyimpanan). Desain peletakan area penyimpanan awal dan area penyimpanan usulan.

\section{KESIMPULAN DAN SARAN}

Setelah dilakukan pengumpulan data dan pengolahan data dengan menggunakan activity relation chart dan metode shared storage pada tata letak gudang transit di PT. XYZ, maka dapat diambil kesimpulan, yaitu tata letak usulan memiliki usulan terhadap pemindahan beberapa fasilitas yang ada pada gudang transit segingga dapat mengoptimalkan kapasitas gudang transit dengan kapasitas awal sebesar 44 area penyimpanan dan pada nilai tata letak usulan memiliki kapasitas sebesar 61 area penyimpanan, dengan ini maka kapasitas tata letak usulan nilainya lebih besar dari tata letak awal.

Pada metode shared storage memiliki total jarak tempuh yang lebih kecil daripada tata letak awal dengan perbaikan susunan media penyimpanan. Total jarak tempuh pada produk 
A,B,C dengan tata letak awal adalah sebesar 142,376 $\mathrm{m}$. Sedangkan pada tata letak usulan terdapat total jarak tempuh sebesar 94,952m dengan selisih 47,424m dari jarak tempuh tata letak awal, maka hal ini dapat diartikan nilai jaak tempuh usulan lebih kecil daripada nilai jarak tempuh tata letak awal.

Menggunakan metode activity relation chart dan shared storagesangat baik bila diterapkan di perusahaan bagian produksi khususnya pada area gudang transit karena secra matematis dapat mengoptimalkan kapasitas area transit dan meminimalisasi jarak tempuhhandklift.Dan perlu Perhatian khusus dalam penempatan barang jadi dalam gudang transit untuk meningkatkan keefektivitasan kerja.

Gambar Sebelum Perbaikan

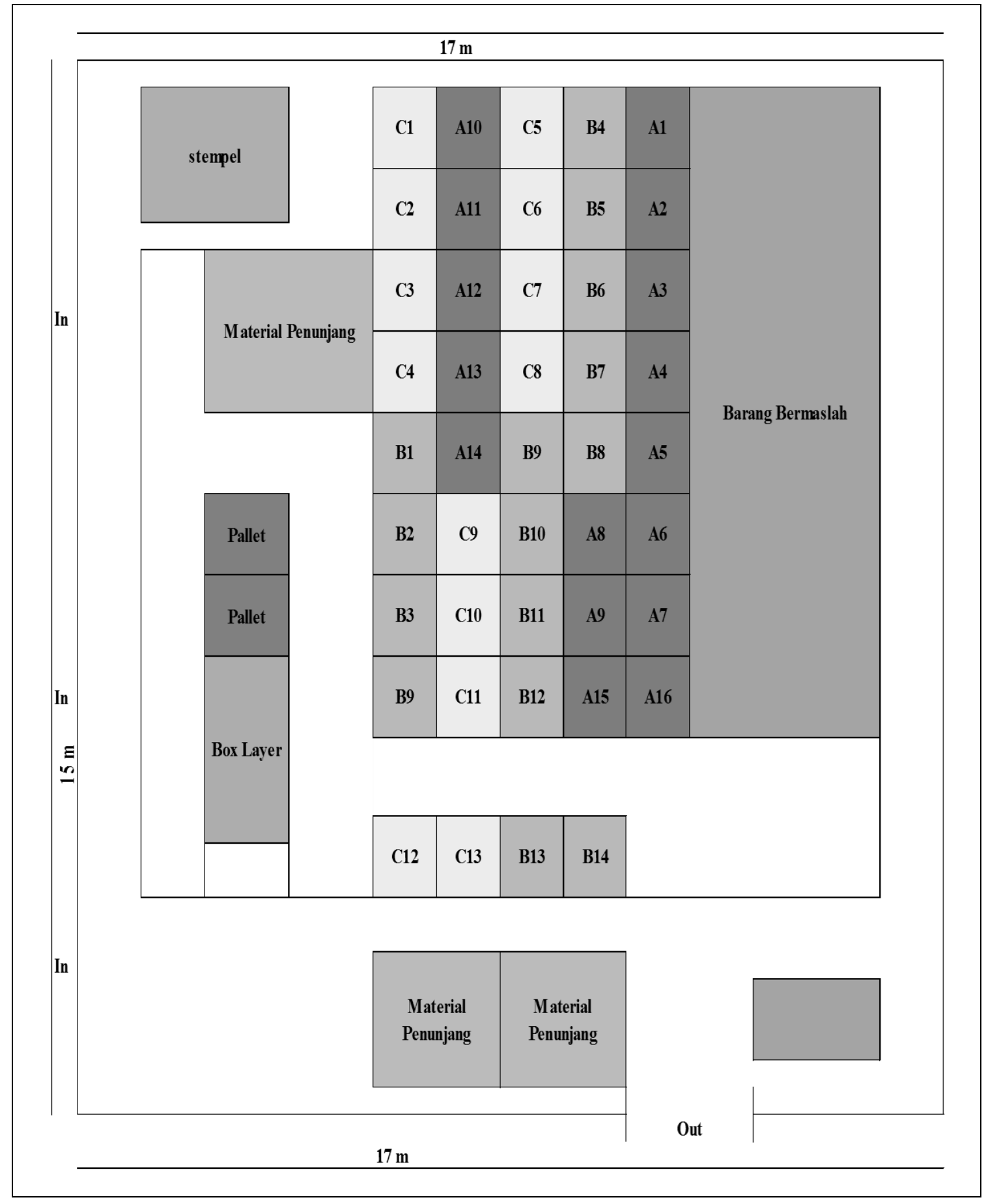


Gambar Usulan Perbaikan

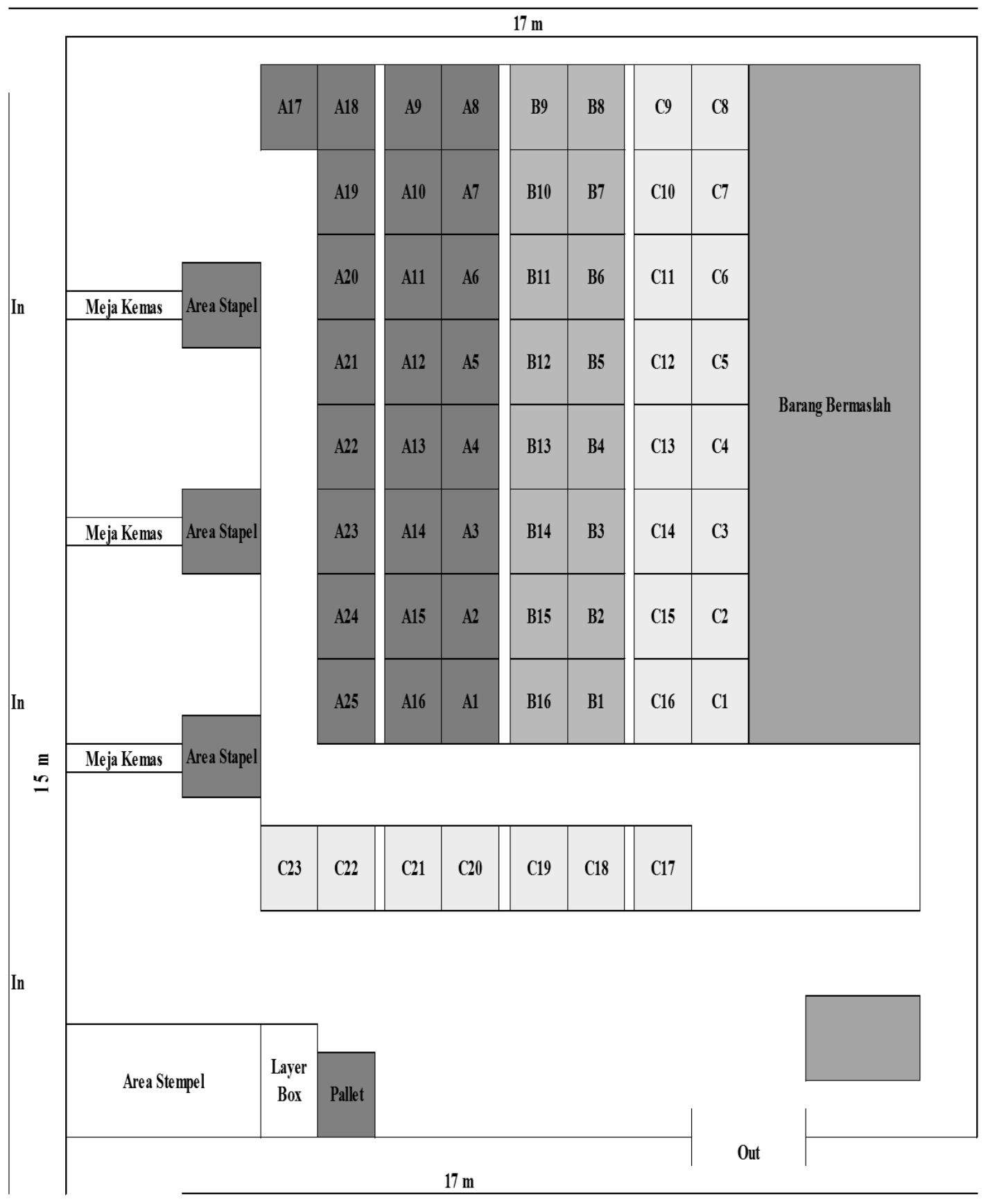




\section{DAFTAR PUSTAKA}

[1] Hidayat (2012), “ perancangan tata letak gudang dengan metoda Class-Based Storage, JURNAL ALAZHAR INDONESIA SERI SAINS DAN TEKNOLOGI, VOL. 1, NO. 3, MARET 2012.

[2] Kurniawan (2014), "perbaikan tata letak gudang pada pr sukun sigaret menggunakan metode shared storage" [Tugas Akhir]. Universitas Dian Nuswantoro Semarang.

[3] Kuswoyo (2015), "usulan pebaikan tata letak gudang raw material chemical menggunakan metode shared storage dan rel space”.[Tugas Akhir]. Fakultas Teknik Industri Universitas Muhammadiyah Sidoarjo.

[4] Sukania (2013), “usulan peningkatan produktivitas melalui perancagan ulang tata letak fasilitas produksi studi kasus di PT.X”,JURNAL TEKNOLOGI VOL. 9 NO. 2 (JULI 2013).

[5] Sritomo Wighjosoebroto (2003), “ Tata Letak Pabrik Dan Pemindahan Bahan” Edisi Ketiga, Institut Teknologi Sepuluh Nopember.

[6] Nasution (2015), "Rancangan Ulang Tata Letak Mesin Di PT. KOROSI SPECINDO" Jurnal Ilmiah Teknik Industri (2015). Vol. 3 No.1,33-44.

[7] Hadiguna,ST,MT Dan Setiawan, (2008), "Tata Letak Pabrik” Andi, Jl.BO 38-40, Telp. (0274) 561881 (Hunting), Fax. (0274) 588282 Yogyakarta.

[8] APPLE, J.M,. "Tata Letak Pabrik Dan Pemindahan Bahan" Edisi Ketiga. Penerjemah; Nurhayati Mardiono. Bandung: Penerbit ITB. 2004.

[9] Rengganis, (2015)"Perbandingan Optimasi Re-Layout Penempatan Fasilitas Produksi Dengan Menggunakan Craft" Volume VII, Nomor 1, Mei 2015. 